\title{
Os rendimentos das aposentadorias e pensões e a concentração de renda: o caso do Paraná - 1992 a 2003
}

\author{
Solange de Cássia Inforzato de Souza ${ }^{1}$ \\ Carlos Roberto Ferreira ${ }^{2}$
}

Resumo: Este trabalho tem como objetivo analisar a participação e a contribuição do componente rendimento domiciliar "aposentadorias e pensões" para a desigualdade da distribuição do rendimento domiciliar per capita no Brasil, Brasil rural, Estado do Paraná e Paraná rural, no período de 1992 a 2003. Para isto, revisa a literatura sobre política social e previdência social no país e utiliza a metodologia de decomposição do índice de Gini dos componentes: rendimento do trabalho principal, rendimento de outros trabalhos, aposentadorias e pensões, doações, rendimentos de aluguel e outros rendimentos (juros, dividendos, etc.). Destaca-se, nos resultados, a crescente participação das aposentadorias e pensões nos anos pós-1992, explicada pelas políticas sociais e econômicas do período. A contribuição dessa parcela de rendimento domiciliar para a concentração de renda é significativa para o Brasil e Brasil rural nos últimos cinco anos analisados. O Paraná contrariou a realidade brasileira, evidenciando a não contribuição dos rendimentos das aposentadorias para a concentração de renda no Estado, com exceção de 2002. No espaço rural, no entanto, a concentração de renda foi produzida por essa parcela de rendimentos nos anos 1992, 1998 e 2002.

Palavras-chave: Previdência social; aposentadorias e pensões; concentração de renda.

1 Professora Adjunta da Universidade Estadual de Londrina. Rua Santos, 777/202, Londrina (PR), CEP 86020-041. E-mail: soinfor@uel.br

2 Professor Adjunto da Universidade Estadual de Londrina. Rua Jorge Velho, 529/74, Londrina (PR), CEP 86010-6oo. E-mail: robert@uel.br 
SOUZA, S. C. I. DE; FERREIRA, C. R. Os rendimentos das aposentadorias...

\title{
Pensions and income concentration: the case of Paraná, 1992-2003
}

\begin{abstract}
This work analyzes the participation and the contribution of the household pensions on the inequality of income distribution in Brazil, Rural Brazil, State of Paraná and Rural Paraná, in the period 1992 - 2003. The paper reviews the literature on social politics and social welfare and uses the methodology of decomposition of the Gini index: revenue of the main work, revenue of other works, pensions, donations, rent revenues and other revenues (interests, dividends, etc.). The results show growing participation of pensions in the years after 1992, explained by the social and economical policies of the period. The contribution of that portion of household revenue for the concentration of income is significant for Brazil and rural Brazil in the last five years analyzed. Paraná thwarted the Brazilian reality, showing the non contribution of pensions for the concentration of income in the State, except for 2002. In the rural space, however, the concentration of income was produced by that portion of revenue in the years 1992, 1998 and 2002.
\end{abstract}

Key words: pension systems; social welfare; pensions; income concentration.

JEL: D31; D63

\section{Introdução}

O debate sobre a Previdência social brasileira intensificou-se a partir da segunda metade da década de 1990, em conseqüência dos seus significativos e crescentes resultados deficitários, particularmente evidenciados pelo comportamento do resultado financeiro do Regime Geral da Previdência Social (RGPS) para o setor privado (32 bilhões de Reais em 2004) e do Regime Jurídico Único (RJU) para o funcionalismo federal (31,7 bilhões de Reais em 2004). As despesas previdenciárias representaram, em 2004, 9,6\% do Produto Interno Bruto (PIB), sendo que o total dos gastos sociais diretos do governo federal compreendeu $14,2 \%$ do PIB. A desagregação dos dados indica que as despesas previdenciárias do RGPS significaram 7,35\% do PIB em 2004 (em 1998 esse número era de 5,63\%) e do RJU, 2,26\% (em 1998 o valor era 2,27\%) .

Os constrangimentos financeiros da previdência social são atribuídos a um conjunto de fatores que derivam do seu quadro institucional, gerencial e estrutural. $\mathrm{O}$ complexo institucional previdenciário está assentado no modelo de repartição simples, cuja lógica pressupõe que as contribuições pagas pelos trabalhadores ativos destinam-se a cobrir os gastos com benefícios dos inativos. O comportamento das variáveis

3 Ver Brasil (2005). 
demográficas, que denuncia aumento da expectativa de sobrevida da população e queda da fecundidade, as mudanças na composição do mercado de trabalho, com redução das contribuições previdenciárias, e a Constituição de 1988, que ampliou os benefícios, comprometem o sistema previdenciário, ao mesmo tempo em que o país revela, historicamente, expressiva concentração de renda e fragilidades das políticas sociais e de mercado de trabalho.

No âmbito do mercado de trabalho, observa-se a elevação da taxa de desemprego aberto, medida pelo IBGE/PME - Pesquisa Mensal do Emprego, de 5,6\% da PEA em 1992, para 9,71\% em 2005, bem como as transformações setoriais do emprego caracterizadas pelo recuo da participação do emprego industrial e pelo processo de informalização das relações de trabalho. Em 2002, as relações informais de trabalho representavam 50,04\% da população ocupada, o que significa perda de arrecadação tributária e constrangimentos no sistema de previdência social, pois que o financiamento da previdência social responde por quase um terço da carga tributária do Brasil (Ramos \& Britto 2004).

Camarano (2002) incorpora uma outra preocupação acerca do crescimento da população brasileira maior de 60 anos, estimando que em 2020 aproximadamente $15 \%$ da população será composta por idosos. Em 2002, o Brasil tinha 16.022.231 pessoas com mais de 60 anos, sendo que $7,77 \%$ eram aposentados ou pensionistas (IBGE 2002).

A literatura aponta também, nesse debate, que o Brasil ocupa o oitavo lugar em concentração de renda no mundo, de acordo com PNUD (2006), e, ainda, que aproximadamente $47 \%$ da renda é apropriada pelos $10 \%$ mais ricos, enquanto que os $50 \%$ mais pobres ficam com $12,7 \%$ da renda. Em 2001, as pessoas que compunham os $10 \%$ mais ricos detinham uma renda 3,7 vezes maior do que toda a renda dos 50\% mais pobres (Ferreira \& Souza 2004a). Outra importante verificação dos pesquisadores na área [(Ferreira \& Souza 2004a); Medeiros (2006); Barros et al. (2006)] é a de que o índice de Gini vem desacelerando no pós-1990, mais intensamente nos anos iniciais do século XXI.

As aposentadorias e pensões, componentes do rendimento domiciliar, contribuem para a concentração de renda no Brasil, pela constatação realizada em Ferreira e Souza (2004a), muito embora a previdência social do Brasil apresente-se como um dos mais importantes instrumentos de política pública e base de sustentação da economia de um grande número de municípios brasileiros de baixa renda, constituindose substantivas possibilidades incrementais de renda domiciliar.

Em estudo realizado anteriormente para o triênio 1999, 2001 e 2002, para o Estado do Paraná, Ferreira e Souza (2004b) detectaram que os rendimentos das aposentadorias e pensões, com exceção de 2002, não 
colaboraram para a concentração de renda no Estado, contrariando a tendência brasileira. A partir das constatações das ocorrências de 1999 e 2001, sugeriu-se uma atualização dos dados para 2003, também concedendo maior amplitude de tempo de análise.

Desse modo, este trabalho intenciona analisar a participação das aposentadorias e pensões no rendimento domiciliar e a magnitude de sua contribuição para a concentração de renda no Brasil e no Paraná, de 1992 a 2003, através da decomposição do índice de Gini, tendo como base de informações as PNADs - Pesquisas Nacionais por Amostra de Domicílios - desse período.

Na seção dois, organiza a revisão de literatura sobre a política social e a experiência recente da previdência social no Brasil. Na terceira seção, indica os procedimentos metodológicos para o desenvolvimento da pesquisa para, na quarta seção, analisar os resultados da decomposição do índice de Gini. Encerrando este texto, as considerações finais são apresentadas.

\section{Políticas de bem-estar e previdência social no Brasil}

Desde os anos 30, o sistema econômico contemplou a construção de uma esfera pública, de um padrão de financiamento público assentado no fundo público, que passa a ser premissa fundamental para a reprodução do capital e da força de trabalho. Do lado da acumulação do capital, o fundo público toma a forma de títulos públicos, subsídios e incentivos, revoluciona as condições de circulação do capital; como forma de financiamento da reprodução da força de trabalho, o fundo público constitui-se em despesas públicas em bens e serviços sociais, como saúde, previdência e outras (Oliveira 1998).

O Brasil, em 1980, ao lado de países latino-americanos como Argentina, Costa Rica, Chile e México, havia alcançado um estágio de conformação de seu sistema de proteção social entendido como um "conjunto articulado de ações públicas e privadas nas áreas de saúde, previdência e assistência social, educação básica e habitação popular" (Draibe 1993: 6), ainda que seu processo de constituição tenha a natureza e substância do tipo meritocrático-particularista (Titmus apud Giovanni 1998) ou conservador corporativista (Esping-Andersen 1991).

O sistema de proteção social brasileiro esteve fundado nas capacidades individuais e na produtividade, com as políticas sociais corrigindo as falhas do mercado, vinculando o acesso aos benefícios sociais ao emprego. Draibe (1993) observa que, pela organização de sistemas estratificados e corporativos, o Brasil integra um grupo de países latino- 
americanos que foram os pioneiros na introdução de sistemas estratificados por grupos profissionais, tipos e valores de benefícios e administrados por várias instituições, o que dificultou a universalização dos direitos sociais. Através de mecanismos de cooptação, com incorporação regulada da classe trabalhadora e controle corporativo, foi-se processando a política social brasileira.

Com o advento da Nova República, há um movimento mais intenso no sistema de proteção concebido num projeto reformador (Fagnani 1997) e que culminou com o momento de reestruturação da política social no Brasil, com a Carta de 1988, particularmente no campo trabalhista e da seguridade social.

Sob o conceito de seguridade social, foram ampliadas as concepções relativas à previdência, saúde e assistência social, seu modo de financiamento, redefinição dos planos de benefícios e formas de organização que apontam para o aumento na universalização do acesso, dos direitos e da descentralização das ações. No caso da previdência, o texto constitucional contribuiu para a igualização dos benefícios dos trabalhadores urbanos e rurais e alteração de valores, apresentando resultados financeiros satisfatórios até 1994. A partir de 1995 as contas da Previdência Social passaram a ser deficitárias, conforme mostra a tabela 1. Marques (1997) e Fagnani $(1997,1999)$ apontam para o entendimento desse déficit como conseqüência de políticas anteriores dos anos 70.

TABELA 1 - BRASIL: EVOLUÇÃO DO DÉFICIT DA PREVIDÊNCIA SOCIAL - \% DO PIB, DE 1995 A 2004.

\begin{tabular}{l|cccccccccc}
\hline $\begin{array}{l}\text { Déficit } \\
\text { (\% }\end{array}$ & \multicolumn{10}{|c}{ ANOS } \\
\cline { 2 - 12 } & 1995 & 1996 & 1997 & 1998 & 1999 & 2000 & 2001 & 2002 & 2003 & 2004 \\
\hline TIB) & 2,8 & 3,8 & 3,7 & 4,4 & 4,7 & 4,8 & 5,3 & 5,2 & 5,6 & 5,3 \\
\hline
\end{tabular}

FONTE: Giambiagi et al. (2004).

No âmbito do orçamento da seguridade, pretendia-se integrar os padrões de financiamento (impostos e contribuição social) e os orçamentos fiscal e da seguridade. Esse último estabelecia como prioridade os direitos sociais e tornava impositiva a busca de novas fontes de recursos para os programas (Dain \& Soares 1998). Como lembrado neste texto mais à frente, a implementação dessa medida foi comprometida pela crise econômica e pelo fracasso do governo Collor.

Entre o final de 1988 e início de 90, fase da regulamentação do processo constitucional, retardou-se a efetivação dos novos direitos, embaraçando tal processo, principalmente com o financiamento da seguridade, destacando o pagamento dos encargos previdenciários da União com recursos da seguridade e a retenção dos repasses das contribuições sociais pelo tesouro Nacional (Azeredo apud Fagnani 1997). Além do mais, 
por meio de medidas provisórias, o executivo federal ora vinculava ora desvinculava os benefícios previdenciários ao salário mínimo e indexava ao índice de preços ao consumidor (IPC).

A década da democratização e dos avanços na proteção social e de crise econômica terminou sentindo as conseqüências do ajuste recessivo que redundou na crise do Estado e do mercado de trabalho.

A década de 90 iniciou-se com a política social perdendo a centralidade. Antes mesmo da implantação de suas diretrizes, o contexto econômico e político foi desfavorável à sua consecução $0^{4}$.

Se na década anterior e nos primeiros anos de 90, o volume arrecadado pelas contribuições de empregados e empregadores permitia financiar a totalidade dos benefícios previdenciários, a situação se agravou no pós-94. Pode-se apontar os determinantes dessa situação. De acordo com Marques (1997), houve aumento dos gastos com benefícios de 1992 para 1993 da ordem de 24,4\%, e, em relação a 1988, de 70,4\%. Concorreram para isso, primeiramente, a existência de demanda reprimida por conta da expectativa de que a Constituição viesse melhorar as condições de acesso e valor dos benefícios, a imposição da justiça brasileira para o pagamento de direitos atrasados, o represamento de pagamentos entre janeiro e outubro de 1992, e, já em 1994, uma ação de antecipação da demanda diante das possíveis mudanças do governo em relação à previdência social.

Em segundo lugar, há que se verificar que os ingressos de novos contribuintes na década de 70 refletiram num incremento de beneficiários nos anos 90, ao mesmo tempo em que nessa última década desestruturava-se o mercado de trabalho com reduzida capacidade contributiva. Ramos \& Reis (1997) e Ramos \& Britto (2004) evidenciam o crescimento da informalidade, que passou de 40\% em 1991 para $51 \%$ da população economicamente ativa (PEA) em meados de 2000, baseados nos dados da Pesquisa Mensal de Emprego (PME) do Instituto Brasileiro de Geografia e Estatística (IBGE). O fraco desempenho do emprego assalariado com carteira e o aumento dos empregadores e dos trabalhadores por conta própria, sem contribuição para a previdência, são fatos que colaboram para intensificar a problemática vivenciada na década de 90 .

Além dos problemas expostos, as modificações na estrutura demográfica e o envelhecimento da população tornam-se incompatíveis com as condições de acesso à aposentadoria, entre outros aspectos. ${ }^{5}$

\footnotetext{
4 Marques (1997) escreve que, no próprio momento de promulgação da Constituição, o então presidente da República alertava, em cadeia nacional, que os novos direitos sociais e previdenciários inviabilizariam o sistema - várias medidas provisórias foram baixadas para dificultar esses direitos.

5 Marques (1997: 159) cita outros problemas.
} 
Insistindo na discussão sobre o desenvolvimento social nos anos 90, pode-se sintetizar que a proposta da estabilidade e retomada do crescimento para a promoção do bem-estar social mostrou-se contraditória, fragilizando as políticas sociais, já que desorganizou o mercado de trabalho brasileiro e conduziu ao crescimento da dívida pública interna, de $\mathrm{R} \$ 60$ bilhões em 1994 para mais de $\mathrm{R} \$ 320$ bilhões em 98, chegando em 2005 em R 1 trilhão.

As políticas passivas e ativas do mercado de trabalho, como as do seguro-desemprego (Azeredo 1998), qualificação profissional (Souza 2002), intermediação de mão-de-obra e geração de emprego e renda (Valle 1998), apresentaram-se insuficientes diante da magnitude da desorganização, precariedade e flexibilidade do mercado de trabalho, uma das faces mais contundentes da exclusão econômica no país (Singer 1998). Ademais, afetam financeiramente as fontes fiscais e contribuições sociais, fontes de recursos para a política social vinculada ao mercado formal de trabalho.

Inauguram-se, diante desse panorama, as reformas da previdência, como a Emenda Constitucional (EC) n. 20 e a lei 9717/98, que buscavam atingir o regime de previdência do setor público, especialmente. Em 1998, as despesas com esse regime totalizavam $\mathrm{R} \$ 20,9$ bilhões, sendo que a contribuição dos servidores era de $\mathrm{R} \$ 2,6$ bilhões, cobertas pelo Tesouro. No âmbito do regime geral da previdência social, os desequilíbrios financeiros foram evidentes no pós-1994, colaborando para isso a estagnação econômica e as mudanças no mercado de trabalho. Daí que entre 1995 e 1998 viabilizaram-se outras medidas, como a substituição do tempo de serviço por tempo de contribuição, o que limita o acesso das camadas mais desfavorecidas diante das características do mercado de trabalho dos anos 90. Diante do comprometimento do ajuste fiscal e da própria estabilização, evidencia-se a urgência das reformas da previdência, favorecidas pelo ambiente de desconforto em relação ao Estado e à esfera pública. ${ }^{6}$

A agenda de reformas da previdência seguiu para os anos iniciais do século XXI, agora também sustentadas na amplitude dos gastos sociais e na participação das despesas da Previdência nos gastos sociais totais do governo, conforme se pode observar na tabela 2 .

6 Oliveira (1998) mostra como se operou o deslocamento da esfera pública para o privado, ao que ele denomina despublicização - movimento contrário ao ocorrido entre 1930 e 80 . 
SOUZA, S. C. I. DE; FERREIRA, C. R. Os rendimentos das aposentadorias...

TABELA 2 - BRASIL: GASTOS SOCIAIS E DESPESA COM BENEFÍCIOS PREVIDENCIÁRIOS DO GOVERNO FEDERAL, EM PERCENTUAL DO PIB, DE 1995 A 2004.

\begin{tabular}{l|c|c|c|c|c|c|c|c|c|c}
\hline \multirow{2}{*}{ Despesas } & \multicolumn{10}{c}{ ANOS } \\
\cline { 2 - 12 } & 1995 & 1996 & 1997 & 1998 & 1999 & 2000 & 2001 & 2002 & 2003 & 2004 \\
\hline Área social & 11,8 & 11,5 & 11,4 & 11,9 & 12,6 & 12,7 & 13,4 & 13,7 & 13,8 & 14,2 \\
Benefícios & 7,3 & 7,5 & 7,4 & 8,0 & 8,3 & 8,2 & 8,7 & 8,9 & 9,5 & 9,7 \\
\hline
\end{tabular}

FONTE: Brasil (2005).

\section{Base de dados e metodologia}

O presente estudo tem por base as informações coletadas nas Pesquisas Nacionais por Amostra de Domicílios (PNAD), no período de 1992 a 2003. A PNAD tem periodicidade anual desde 1971, sendo interrompida por ocasião dos Censos Demográficos (1970, 1980, 1991 e 2000). Trata-se de um levantamento anual realizado por meio de uma amostra dos domicílios que abrange todo o país, exceto a área rural dos estados da antiga região Norte (Acre, Amapá, Amazonas, Pará, Rondônia e Roraima). Para as pesquisas da década de 90 e anos posteriores, essa abrangência geográfica foi mantida, ou seja, a PNAD continuou a cobrir todo o país, com exceção da área rural dessas seis unidades da federação.

Por essa pesquisa são investigados, de forma permanente, os temas habitação, rendimento e trabalho, associados a aspectos demográficos e educacionais, bem como outros assuntos de caráter demográfico, social e econômico com periodicidade variável. É uma coleta oficial de dados, realizada sob a responsabilidade do Departamento de Emprego e Rendimento da Diretoria de Pesquisa da Fundação Instituto Brasileiro de Geografia e Estatística - IBGE.

A comparação dos resultados da PNAD a partir de 1992 com os das décadas anteriores deve levar em conta que a classificação das áreas urbanas e rurais é feita de acordo com a legislação vigente por ocasião dos censos demográficos. Dessa forma, manteve-se a delimitação das áreas urbanas e rurais no período intercensitário, mesmo que a legislação a tenha alterado. Para as pesquisas da PNAD de 1992 a 1999, utilizou-se a classificação vigente por ocasião do Censo Demográfico de 1991 e para a pesquisa da PNAD de 2001 a 2003, utilizou-se a classificação vigente por ocasião do Censo Demográfico de 2000. Por razões excepcionais, não foi realizada a pesquisa em 1994. Dessa forma, as estatísticas por situação urbana e rural não captam integralmente a sua evolução, sendo que as diferenças se intensificam na medida em que os resultados obtidos se afastam do ano de realização do Censo Demográfico. 
Ressalta-se também que, para as PNADs de 1992 a 1996, foram utilizados os fatores de expansão corrigidos com base na contagem populacional e divulgados juntamente com os microdados da PNAD de 1997.

As informações utilizadas ${ }^{7}$ referem-se a dados individuais das PNADs de 1992, 1993, 1995, 1996, 1997, 1998, 1999, 2001, 2002 e 2003, fornecidas pelo IBGE, através de CD-ROM anual.

O procedimento metodológico adotado pelo IBGE implica que cada pessoa da amostra representa um determinado número de pessoas da população. Os dados individuais são fornecidos com o peso ou fator de expansão de cada indivíduo. Isso permite que os cálculos sejam elaborados ponderando-se cada observação pelo respectivo peso. Todos os cálculos, neste trabalho, foram feitos considerando o peso ou fator de expansão de cada domicílio da amostra da PNAD, fornecido pelo IBGE, analisados apenas os domicílios particulares permanentes com declaração do rendimento domiciliar. Domicílios com rendimentos não declarados foram excluídos da análise.

As informações das PNADs são de boa qualidade, mas é preciso observar algumas características da natureza desses dados, as quais são restrições que precisam ser levadas em consideração na análise dos resultados, conforme alerta Hoffmann (1988 e 2002a).

De acordo com as notas metodológicas do IBGE (2001), "considerou-se como rendimento mensal domiciliar a soma dos rendimentos mensais dos moradores do domicílio, exclusive os das pessoas cuja condição no domicílio fosse pensionista, empregado doméstico ou parente do empregado doméstico". Para se obter o rendimento domiciliar per capita, dividiu-se o rendimento mensal domiciliar pelo número de pessoas do domicílio, excluindo pensionistas, empregados domésticos e seus parentes.

Os rendimentos de aposentadorias e pensões são aqueles pagos pelo governo federal ou por instituto de previdência, entidades seguradoras ou fundos de pensão; e, finalmente, juros, etc., são decorrentes de aplicações financeiras em ativos financeiros de renda fixa, caderneta de poupança e outros. (IBGE 2001)

Para a elaboração dos dados a partir das PNADs dividiu-se o estudo em quatro regiões denominadas: Brasil, Brasil rural, Paraná e Paraná rural. Ressalta-se que os rendimentos recebidos das aposentadorias e pensões que compõem os rendimentos domiciliares estão localizados nas áreas rural e urbana, não havendo discriminação no interior desse com- 
ponente com relação a sua origem, ou seja, o recorte rural significa os rendimentos das aposentadorias e pensões recebidas nos domicílios da área rural.

\subsection{Metodologia}

Utilizou-se a decomposição do Índice de Gini $^{8}$ para analisar a contribuição das aposentadorias e pensões para a desigualdade da distribuição do rendimento domiciliar per capita no Brasil, Brasil rural, Paraná e Paraná rural, na década de 90 e anos posteriores, 2001, 2002 e 2003. Essa decomposição da desigualdade considera os vários componentes que se somam para formar os rendimentos domiciliares 9 : trabalho principal, outros trabalhos, aposentadorias e pensões, aluguéis, doações, juros, etc.

2.1.1 Decomposição do índice de Gini

A metodologia de decomposição do coeficiente de Gini utilizada neste trabalho está baseada em Pyatt et al. (1980) ${ }^{10}$. O ponto inicial é assumir que há $n$ pessoas e que $z_{i}$ e $t_{i}$ são duas variáveis quaisquer observadas nas pessoas com $(i=1,2, \ldots, n)$. As pessoas terão uma posição de ordem de acordo com $t_{i}$ : a posição da pessoa na colocação $i$ será denominada $r\left(t_{i}\right)$, com a convenção de que $r\left(t_{i}\right)=1$ para a pessoa com o $t_{i}$ menor e $r\left(t_{i}\right)=n$ para a pessoa com o maior $t_{i}$. Se duas ou mais pessoas tiverem o mesmo valor para $t_{i}$, para cada uma delas será dada a média das posições que essas pessoas poderão ter se houver uma diferença infinitesimal entre elas. Dessa forma, a média de todas as posições $r\left(t_{i}\right)$ é dada por:

$$
\bar{r}=\frac{1}{n} \sum_{i=1}^{n} r\left(t_{i}\right)=\frac{(n+1)}{2}
$$

A média das posições é, portanto, independente do critério de "posicionamento" $t_{i}$ que é dado.

Admite-se que o valor médio de $z_{i}$ é positivo, isto é,

$$
\bar{z}=\frac{1}{n} \sum_{i=1}^{n} z_{i}>0
$$

Note-se que $z_{i}$ não necessita ser positivo para todo $i$.

8 Realizada pelo software SAS System for Windows V8.

9 Um exemplo numérico de decomposição pode ser encontrado em Ferreira (2003).

10 Essa metodologia já foi utilizada por muitos autores, podendo-se citar Fei et al. (1978), Ercelawn (1984), Mariano \& Lima (1998), Neder (2001), Hoffmann (2002a e 2002b). 
Dado $\bar{z}$ pode-se também definir:

$$
\pi_{i}=\frac{z_{i}}{n \bar{z}}
$$

para cada pessoa. De (2) e (3) tem-se que a soma dos $n$ valores de $\pi_{i}$ é igual a 1.

A curva de concentração de $z_{i}$ em relação a $t_{i}$ mostra como os valores acumulados dos $\pi_{i}$ variam em função de $\frac{r\left(t_{i}\right)}{n}$, tendo-se previamente ordenado as pessoas conforme valores crescentes de $r\left(t_{i}\right)$. Note-se que a curva de concentração não precisa ser monotonicamente crescente. A curva pode ficar acima do bissetor do primeiro quadrante. Se houver valores negativos de $z_{i}$, a curva pode ficar abaixo do eixo das abcissas.

A razão de concentração de $z$ em relação a $t$, indicada por $C(z \mid t)$, é definida como 1 menos duas vezes a área entre a curva de concentração e o eixo das abscissas. Cabe ressaltar que áreas delimitadas pela curva de concentração abaixo do eixo das abscissas são negativas.

Observa-se que a área abaixo da curva de concentração pode ser obtida através da soma das áreas de $n$ trapézios verticais, cada um com altura de $\left(\frac{1}{n}\right)$, isto é, como:

$$
\begin{aligned}
& \delta=\frac{1}{2} \cdot \frac{1}{n}\left[\pi_{1}+\sum_{i=2}^{n}\left(\sum_{j=1}^{i-1} \pi_{j}+\sum_{j=1}^{i} \pi_{j}\right)\right] \\
& \delta=\frac{1}{2} \cdot \frac{1}{n} \sum_{i=1}^{n} \pi_{i}[1+2(n-i)]
\end{aligned}
$$

em que o subscrito $i$ refere-se à posição de ordem da pessoa, ou seja, $i=$ $r\left(t_{i}\right)$.

De (4) tem-se que a razão de concentração é:

$$
C(z \mid t)=1-\frac{1}{n} \sum_{i=1}^{n} \pi_{i}[1+2(n-i)]
$$

Lembrando a expressão (1), após algumas transformações algébricas verifica-se que

$\mathrm{ou}$

$$
\begin{aligned}
& C(z \mid t)=\frac{2}{n} \sum_{i=1}^{n} \pi_{i}\left[r\left(t_{i}\right)-\bar{r}\right] \\
& C(z \mid t)=2 \operatorname{cov}[\pi(z), r(t)]
\end{aligned}
$$


SOUZA, S. C. I. DE; FERREIRA, C. R. Os rendimentos das aposentadorias...

em que $\operatorname{cov}(a, b)$ é a covariância entre as variáveis $a$ e $b$. Utilizando (3), segue-se que

ou

$$
C(z \mid t)=2 \operatorname{cov}\left[\left(\frac{z}{n \bar{z}}\right) r(t)\right]
$$

$$
C(z \mid t)=\frac{2}{n \bar{z}} \operatorname{cov}[z, r(t)]
$$

Se a variável $z$ for não-negativa $\left(z_{i} \geqslant 0\right.$ para todo $\left.i\right)$, verifica-se que a área abaixo da curva de concentração varia de $(2 n)^{-1}$ a $1-(2 n)^{-1}$, de maneira que $\frac{1}{n}-1 \leq C(z \mid t) \leq 1-\frac{1}{n}$

No caso particular em que a própria variável $z$ for utilizada para ordenar os valores, isto é, se $t=z$, a curva de concentração passa a ser a curva de Lorenz da distribuição de $z$ e a razão de concentração é o respectivo índice de Gini.

Se $y_{i}$ é a renda domiciliar per capita e as pessoas estiverem ordenadas conforme o valor dessa mesma variável, o índice de Gini da renda domiciliar per capita é

$$
G(y)=C(y \mid y)=\frac{2}{n \bar{z}} \operatorname{cov}[y, r(y)]
$$

Se $x_{i k}$ é a contribuição da parcela $k$ (por exemplo, a aposentadoria) para a renda domiciliar per capita $y_{i}$, então:

$$
y_{i}=\sum_{k=1}^{m} x_{i k} \text { para } i=1, \ldots, n
$$

em que a renda total é constituída por $m$ parcelas $(k=1, \ldots, m)$. Segue-se que

$$
\bar{y}=\sum_{k=1}^{m} \bar{x}_{k}
$$

em que $\bar{x}_{k}$ é a média de $x_{i k}$ para as $n$ pessoas.

Substituindo (9) em (8), tem-se:

$$
G(y)=\frac{2}{n \bar{z}} \operatorname{cov}\left[\sum_{k} x_{i k}, r(y)\right]
$$

Lembrando (7), verifica-se que

em que:

$$
G(y)=\sum_{k=1}^{m} \phi_{k} C\left(x_{k} \mid y\right)
$$

$$
\phi_{k}=\frac{\bar{x}_{k}}{\bar{y}}
$$


Note-se que $\phi_{K}$ é a participação da $k$-ésima parcela na renda total.

É interessante verificar como a razão de concentração de $x_{k}$ em relação a $y$ se relaciona com o índice de Gini de $x_{k}$, que é dado por

$$
G\left(x_{k}\right)=\frac{2}{n \bar{x}_{k}} \operatorname{cov}\left[x_{k}, r\left(x_{k}\right)\right]
$$

Usando (7), tem-se:

$$
\frac{C\left(x_{k} \mid y\right)}{G\left(x_{k}\right)}=\frac{\operatorname{cov}\left[x_{k}, r(y)\right]}{\operatorname{cov}\left[x_{k}, r\left(x_{k}\right)\right]}=R\left(y, x_{k}\right)
$$

$R\left(y, x_{k}\right)$ é denominada razão de correlação de ordem, cabendo ressaltar que não é um coeficiente de correlação de ordem. A expressão (14) mostra que a razão será igual a um somente se:

$$
r(y)=r\left(x_{k}\right)
$$

ou seja, somente se as pessoas tiverem o mesmo ordenamento com respeito à parcela de renda $k$ e com respeito à renda domiciliar per capita.

Para obter $G\left(x_{k}\right)$, as pessoas são ordenadas conforme valores crescentes de $x_{i k}$. Em geral, o ordenamento será diferente no cálculo de $C\left(x_{k} \mid y\right)$ quando as pessoas são ordenadas pelo valor de $y_{i}$. É claro que o valor acumulado dos $x_{i k}$ até uma posição $h$ será mínimo quando a ordenação tiver sido feita conforme os próprios valores de $x_{i k}$. Em outras palavras, a curva de concentração de $x_{k}$ em relação a $y$ nunca poderá ficar abaixo da curva de Lorenz de $x_{k}$. Conseqüentemente, a razão de concentração de $x_{k} \mathrm{em}$ relação a $y$ não pode exceder o índice de Gini de $x_{k}$, isto é,

$$
\frac{C\left(x_{k} \mid y\right)}{G\left(x_{k}\right)}=R\left(y, x_{k}\right)=R_{k} \leq 1
$$

Esse resultado também poderia ser obtido considerando que

$\operatorname{cov}[z, r(z)] \geq \operatorname{cov}[z, r(t)]$ para todo $t$.

Hoffmann (2002a) observa que, na expressão (11), se todas as razões de concentração tivessem o mesmo valor, esse seria também o valor de $G(y)$. Dessa forma, ele considera que um componente $x_{i k}$ contribui para aumentar a desigualdade quando $C\left(x_{k} \mid y\right)>G(y)$.

Quando $C\left(x_{k} \mid y\right)<G(y)$, o componente $x_{i k}$ já está contribuindo para reduzir a desigualdade em relação àquela situação hipotética de igualdade das razões de concentração. 
SOUZA, S. C. I. DE; FERREIRA, C. R. Os rendimentos das aposentadorias...

\section{A decomposição do índice de Gini para o Brasil, Brasil rural, Paraná e Paraná rural}

A utilização da metodologia de decomposição do índice de Gini conforme parcelas do rendimento domiciliar per capita permite observar a participação de cada componente na formação do Gini global, para cada ano analisado. Especial atenção é dada ao rendimento das aposentadorias e pensões, objeto de estudo neste trabalho.

A tabela 3 mostra a participação percentual dos componentes do rendimento domiciliar per capita para o Brasil, de 1992 a 2003. Observa-se que os rendimentos do trabalho principal contribuem com a maior parcela no total dos rendimentos para o Brasil. Nota-se que a taxa de crescimento do (\%) $\phi_{K}$ é negativa, ou seja, no período em estudo, a taxa composta de crescimento ${ }^{11}$ (TCC) da parcela do trabalho principal diminuiu $0,8 \%$ ao ano.

As aposentadorias e pensões contribuem com a segunda maior parcela no total dos rendimentos. Esse componente, ao longo do período analisado, teve a sua TCC aumentando em 4,3\% ao ano. Entre os anos de 1992 e 1996 a sua participação estava abaixo de $15 \%$, mas em 1997 passa a ser 15,2\% e chega em 2003 com uma participação de 19,8\%.

TABELA 3. PARTICIPAÇÃO PERCENTUAL [(\%) $\left.\phi_{K}\right]$ DOS COMPONENTES DO RENDIMENTO DOMICILIAR PER CAPITA. BRASIL, DE 1992 A 2003 .

\begin{tabular}{|c|c|c|c|c|c|c|c|c|c|c|}
\hline \multirow{2}{*}{ Parcelas } & \multicolumn{10}{|c|}{ Brasil - Participação percentual dos rendimentos $\left[(\%) \phi_{K}\right]$} \\
\hline & 1992 & 1993 & 1995 & 1996 & 1997 & 1998 & 1999 & 2001 & 2002 & 2003 \\
\hline $\begin{array}{l}\text { Trabalho } \\
\text { Principal }\end{array}$ & 79,0 & 78,3 & 78,5 & 78,3 & 78,2 & 76,2 & 75,5 & 74,7 & 74,2 & 73,6 \\
\hline $\begin{array}{l}\text { Outros } \\
\text { trabalhos }\end{array}$ & 2,9 & 3,3 & 3,5 & 3,4 & 3,3 & 3,2 & 3,0 & 3,2 & 3,2 & 3,1 \\
\hline $\begin{array}{l}\text { Aposent. e } \\
\text { pensões }\end{array}$ & 14,2 & 14,1 & 14,2 & 14,5 & 15,2 & 16,7 & 17,8 & 18,5 & 18,7 & 19,8 \\
\hline Aluguel & 1,3 & 1,1 & 2,3 & 2,4 & 2,2 & 2,4 & 2,2 & 1,9 & 1,9 & 1,7 \\
\hline Doações & 0,4 & 0,4 & 0,6 & 0,5 & 0,6 & 0,7 & 0,7 & 0,7 & 0,8 & 0,8 \\
\hline $\begin{array}{c}\text { Outros } \\
\text { rendimentos }\end{array}$ & 2,2 & 2,8 & 0,9 & 0,9 & 0,5 & 0,8 & 0,8 & 0,9 & 1,3 & 1,1 \\
\hline Total & 100,0 & 100,0 & 100,0 & 100,0 & 100,0 & 100,0 & 100,0 & 100,0 & 100,0 & 100,0 \\
\hline
\end{tabular}

FONTE: Elaboração própria dos autores a partir de IBGE - dados individuais das PNADs de 1992 a 2003.

11 A taxa composta de crescimento foi obtida pelo modelo semilog, com nível de significância de $5 \%$. 
A tabela 4 evidencia a participação percentual dos componentes do rendimento domiciliar per capita para o Brasil rural, de 1992 a 2003. Observa-se que nesse período a maior participação foi do trabalho principal, seguido pelas aposentadorias e pensões.

\begin{tabular}{|c|c|c|c|c|c|c|c|c|c|c|}
\hline \multirow{2}{*}{ Parcelas } & \multicolumn{10}{|c|}{ Brasil Rural - Participação percentual dos rendimentos $\left[(\%) \phi_{K}\right]$} \\
\hline & 1992 & 1993 & 1995 & 1996 & 1997 & 1998 & 1999 & 2001 & 2002 & 2003 \\
\hline $\begin{array}{l}\text { Trabalho } \\
\text { Principal }\end{array}$ & 78,4 & 77,6 & 76,2 & 78,6 & 77,2 & 74,5 & 75,4 & 70,3 & 69,4 & 69,9 \\
\hline $\begin{array}{l}\text { Outros } \\
\text { trabalhos }\end{array}$ & 3,4 & 4,6 & 4,9 & 3,9 & 4,2 & 4,3 & 4,3 & 3,9 & 3,7 & 3,2 \\
\hline $\begin{array}{l}\text { Aposent. e } \\
\text { pensões }\end{array}$ & 15,6 & 14,3 & 16,2 & 15,0 & 15,0 & 18,1 & 17,4 & 21,7 & 22,7 & 23,1 \\
\hline Aluguel & 0,5 & 0,9 & 1,4 & 1,2 & 1,4 & 1,4 & 1,4 & 1,6 & 1,1 & 1,2 \\
\hline Doações & 0,4 & 0,4 & 0,7 & 0,6 & 0,7 & 0,7 & 0,7 & 0,5 & 0,6 & 0,5 \\
\hline $\begin{array}{c}\text { Outros } \\
\text { rendimentos }\end{array}$ & 1,7 & 2,2 & 0,6 & 0,7 & 0,6 & 1,0 & 1,0 & 2,0 & 2,5 & 2,2 \\
\hline Total & 100,0 & 100,0 & 100,0 & 100,0 & 100,0 & 100,0 & 100,0 & 100,0 & 100,0 & 100,0 \\
\hline
\end{tabular}

FONTE: Elaboração própria dos autores a partir de IBGE - dados individuais das PNADs de 1992 a 2003.

Entre 1992 e 2003, a participação do trabalho principal no meio rural diminuiu $8,5 \%$, ou teve uma taxa composta de crescimento negativa de $1,4 \%$ ao ano. Em 1992, o trabalho principal participava com $78,4 \%$, chegando em 2003 com 69,9\%.

As aposentadorias e pensões do meio rural, em 1992, participavam com $15,6 \%$ da renda total, chegando em 2003 a 23,1\%, ou seja, um crescimento de $7,5 \%$ ou uma taxa composta de crescimento de $5,5 \%$ ao ano.

A tabela 5 reúne informações sobre a participação percentual dos componentes do rendimento domiciliar per capita no Estado do Paraná, de 1992 a 2003. Há predominância do trabalho principal, seguido pelas aposentadorias e pensões na participação da renda total do estado.

A participação do rendimento do trabalho principal na renda total do estado está um pouco acima da participação desse mesmo rendimento para o Brasil, embora apresente a mesma tendência de decrescimento. Nesse período, para o Paraná, a participação percentual do trabalho principal diminuiu $6,8 \%$. A sua taxa composta de crescimento foi negativa, de $1,1 \%$ ao ano.

A participação do rendimento de aposentadorias e pensões na renda total do estado é menor que a participação desse rendimento no Brasil. No período analisado, o componente aposentadorias e pensões para o 
SOUZA, S. C. I. DE; FERREIRA, C. R. Os rendimentos das aposentadorias...

Paraná cresceu $4,8 \%$ e sua taxa composta de crescimento foi de $5,6 \%$ ao ano, superior à do Brasil.

A tabela 6 mostra a participação percentual dos componentes do rendimento domiciliar per capita no Paraná rural, de 1992 a 2003. Observase que o rendimento do trabalho principal participou com os maiores percentuais em todo o período analisado. De 1992 a 1997, a $\left[(\%) \phi_{K}\right]$ elevouse, o que mostra a participação positiva do meio rural na fase inicial do Plano Real. Entre 1992 e 2003, o [(\%) $\left.\phi_{K}\right]$ recuou 3,8\%, percentual bastante inferior ao do Brasil rural. A taxa composta de crescimento foi negativa, de $0,95 \%$ ao ano.

TABELA 5. PARTICIPAÇÃO PERCENTUAL [(\%) $\left.\phi_{K}\right]$ DOS COMPONENTES DO RENDIMENTO DOMICILIAR PER CAPITA. PARANÁ, DE 1992 A 2003 .

\begin{tabular}{c|cccccccccc}
\hline \multirow{2}{*}{ Parcelas } & \multicolumn{7}{c}{ Paraná - Participação percentual dos rendimentos } & {$\left[(\%) \phi_{K}\right]$} & \\
\cline { 2 - 10 } & 1992 & 1993 & 1995 & 1996 & 1997 & 1998 & 1999 & 2001 & 2002 & 2003 \\
\hline $\begin{array}{c}\text { Trabalho } \\
\text { Principal }\end{array}$ & 82,4 & 82,3 & 81,4 & 79,9 & 81,7 & 79,3 & 78,2 & 76,0 & 76,3 & 75,6 \\
$\begin{array}{c}\text { Outros } \\
\text { trabalhos }\end{array}$ & 2,8 & 2,9 & 3,7 & 4,2 & 3,5 & 3,3 & 3,6 & 4,1 & 3,0 & 3,8 \\
$\begin{array}{c}\text { Aposent. e } \\
\text { pensões }\end{array}$ & 11,2 & 10,4 & 10,7 & 11,4 & 11,0 & 13,2 & 13,5 & 15,7 & 16,2 & 16,0 \\
Aluguel & 1,6 & 1,0 & 2,4 & 2,7 & 2,4 & 2,3 & 3,1 & 2,3 & 2,7 & 2,7 \\
$\begin{array}{c}\text { Doações } \\
\text { Outros }\end{array}$ & 0,3 & 0,3 & 0,6 & 0,6 & 0,5 & 0,6 & 0,6 & 0,5 & 0,7 & 0,7 \\
rendimentos & 1,7 & 1,8 & 1,2 & 1,2 & 0,9 & 1,3 & 1,0 & 1,4 & 1,1 & 1,2 \\
\hline \multicolumn{1}{c}{ Total } & 100,0 & 100,0 & 100,0 & 100,0 & 100,0 & 100,0 & 100,0 & 100,0 & 100,0 & 100,0 \\
\hline
\end{tabular}

FONTE: Elaboração própria dos autores a partir de IBGE - dados individuais das PNADs de 1992 a 2003.

$\mathrm{O}$ rendimento de aposentadorias e pensões do meio rural teve um crescimento de 3,7\% no período 1992/2003. A taxa composta de crescimento foi de $5,2 \%$ ao ano, um pouco abaixo da taxa verificada no Brasil rural e no estado do Paraná.

Pode-se sintetizar alguns movimentos na economia social brasileira no pós-90. O aumento visível das aposentadorias é resultado do conteúdo favorável à seguridade social da Constituição de 1988 e do aumento do volume de contribuintes estimulado na década de 70, que redundou no incremento de beneficiários na década de 90. Especial atenção merece a área rural brasileira, com expressivos incrementos na participação das aposentadorias na renda domiciliar. 
SOUZA, S. C. I. DE; FERREIRA, C. R. Os rendimentos das aposentadorias...

TABELA 6. PARTICIPAÇÃO PERCENTUAL $\left[(\%) \phi_{K}\right]$ DOS COMPONENTES DO RENDIMENTO DOMICILIAR PER CAPITA. PARANÁ RURAL, DE 1992 A 2003.

\begin{tabular}{c|cccccccccc}
\hline \multirow{2}{*}{ Parcelas } & \multicolumn{7}{|c}{ Paraná Rural - Participação percentual dos rendimentos [(\%) $\left.\phi_{K}\right]$} \\
\cline { 2 - 10 } & 1992 & 1993 & 1995 & 1996 & 1997 & 1998 & 1999 & 2001 & 2002 & 2003 \\
\hline $\begin{array}{c}\text { Trabalho } \\
\begin{array}{c}\text { Principal } \\
\text { Outros } \\
\text { trabalhos }\end{array}\end{array}$ & 79,3 & 84,7 & 82,0 & 82,7 & 82,0 & 76,1 & 80,8 & 75,1 & 78,2 & 75,5 \\
$\begin{array}{c}\text { Aposent. e } \\
\text { pensões }\end{array}$ & 12,8 & 4,2 & 3,2 & 3,8 & 3,8 & 3,8 & 3,7 & 3,9 & 4,1 & 2,7 \\
$\begin{array}{c}\text { Aluguel } \\
\text { Doações }\end{array}$ & 0,9 & 0,6 & 1,1 & 0,8 & 1,3 & 0,6 & 1,9 & 1,8 & 0,7 & 4,1 \\
$\begin{array}{c}\text { Outros } \\
\text { rendimentos }\end{array}$ & 4,0 & 1,8 & 0,9 & 0,9 & 0,9 & 4,1 & 0,8 & 2,0 & 1,4 & 1,2 \\
\hline Total & 100,0 & 100,0 & 100,0 & 100,0 & 100,0 & 100,0 & 100,0 & 100,0 & 100,0 & 100,0 \\
\hline
\end{tabular}

FONTE: Elaboração própria dos autores a partir de IBGE - dados individuais das PNADs de 1992 a 2003.

Frente à evolução dessa situação e o comprometimento dos resultados financeiros da previdência social, medidas são tomadas para freá-la na década de 90. Mesmo assim, ocorre com um novo ímpeto no período 1998-2003.

No âmbito do mercado de trabalho, a sua desestruturação e vulnerabilidade podem colaborar para o entendimento dos resultados obtidos na pesquisa. A taxa de desemprego aberto ${ }^{12}$, medida pelo IBGE/ PME - Pesquisa Mensal do Emprego, saltou de 5,7\% da PEA em 1992, para $7,1 \%$ em 2002 e 12,3\% em 2003 (Conjuntura... 2004). Esse desequilíbrio entre a oferta e demanda de trabalho foi favorecido pelas alterações na composição setorial do emprego, com a redução da participação do emprego industrial e ampliação da participação do emprego no setor terciário, tradicionalmente mais suscetível à precarização do trabalho.

A partir de 1990, o número de empregos gerados com carteira assinada passa de um crescimento de 23\% (1986/90) para uma queda de $28 \%$ (1991/97), enquanto o número de trabalhadores sem carteira cresce $5 \%$ no período 1986/90 e 27\% no período 1991/97 (Dupas 1999:126). As relações informais de trabalho se intensificam no final dos anos 90 e início dos 2000, apresentando um valor de 50,04\% da população ocupada ao término de 2002, contrapondo-se a 40\% em 1991 (Ramos \& Britto 2004).

12 Se considerarmos o desemprego aberto e oculto medidos pelo DIEESE para a grande São Paulo, esses valores são 14,9\% em 1992, 19,0\% em 2002 e 19,9\% em 2003. 
SOUZA, S. C. I. DE; FERREIRA, C. R. Os rendimentos das aposentadorias...

A preocupação maior, além das mutações do mercado de trabalho, da pressão populacional em termos de envelhecimento e do embaraço financeiro da previdência social, é que as aposentadorias e pensões contribuem para a concentração de renda no Brasil, mais intensamente no pós-1998, atingindo também a área rural. No entanto, há que se destacar o caso do Paraná. É o que se verá a seguir, objeto do presente estudo.

A tabela 7 mostra a razão de concentração (C) da parcela de aposentadorias e pensões e do trabalho principal, comparativamente ao índice de Gini total, para o Brasil, no período de 1992 a 2003.

Em todo esse período, a parcela trabalho principal não contribui para aumentar a concentração de renda, enquanto que a parcela de aposentadorias e pensões, a partir de 1998 passou a contribuir para a concentração de renda no Brasil.

TABELA 7. RAZÃO DE CONCENTRAÇÃO (C) NA DECOMPOSIÇÃO DO ÍNDICE DE GINI DO RENDIMENTO DOMICILIAR PER CAPITA. BRASIL, DE 1992 A 2003.

\begin{tabular}{|c|c|c|c|c|c|c|c|c|c|c|}
\hline \multirow{2}{*}{ Parcelas } & \multicolumn{10}{|c|}{ Brasil - Razão de concentração } \\
\hline & 1992 & 1993 & 1995 & 1996 & 1997 & 1998 & 1999 & 2001 & 2002 & 2003 \\
\hline $\begin{array}{l}\text { Trabalho } \\
\text { Principal }\end{array}$ & 0,565 & 0,589 & 0,587 & 0,588 & 0,591 & 0,585 & 0,579 & 0,581 & 0,575 & 0,570 \\
\hline $\begin{array}{l}\text { Outros } \\
\text { trabalhos }\end{array}$ & 0,758 & 0,765 & 0,766 & 0,784 & 0,767 & 0,748 & 0,745 & 0,785 & 0,777 & 0,768 \\
\hline $\begin{array}{l}\text { Aposent. e } \\
\text { pensões }\end{array}$ & 0,576 & 0,579 & 0,586 & 0,580 & 0,585 & 0,599 & 0,603 & 0,603 & 0,592 & 0,592 \\
\hline Aluguel & 0,802 & 0,784 & 0,813 & 0,802 & 0,796 & 0,803 & 0,803 & 0,797 & 0,803 & 0,801 \\
\hline Doações & 0,368 & 0,423 & 0,399 & 0,436 & 0,380 & 0,413 & 0,354 & 0,395 & 0,429 & 0,403 \\
\hline $\begin{array}{c}\text { Outros } \\
\text { rendimentos }\end{array}$ & 0,839 & 0,858 & 0,789 & 0,815 & 0,769 & 0,764 & 0,695 & 0,539 & 0,512 & 0,338 \\
\hline Gini Total & 0,580 & 0,602 & 0,599 & 0,600 & 0,600 & 0,598 & 0,592 & 0,594 & 0,587 & 0,581 \\
\hline
\end{tabular}

FONTE: Elaboração própria dos autores a partir de IBGE - dados individuais das PNADs de 1992 a 2003.

Note-se que a razão de concentração de aposentadorias e pensões, ao longo do período analisado, é superior ou está ligeiramente abaixo da razão de concentração do rendimento do trabalho principal. O período de 1998 a 2003 apresenta razão de concentração superior ao índice de Gini e substancialmente maior que a razão de concentração do rendimento do trabalho principal.

A tabela 8 mostra a razão de concentração (C) da parcela de aposentadorias e pensões e do trabalho principal, comparativamente ao índice de Gini total, para o Brasil rural, de 1992 a 2003. 
SOUZA, S. C. I. DE; FERREIRA, C. R. Os rendimentos das aposentadorias...

TABELA 8. RAZÃO DE CONCENTRAÇÃO (C) NA DECOMPOSIÇÃO DO ÍNDICE DE GINI DO RENDIMENTO DOMICILIAR PER CAPITA. BRASIL RURAL, DE 1992 A 2003.

\begin{tabular}{|c|c|c|c|c|c|c|c|c|c|c|}
\hline \multirow{2}{*}{ Parcelas } & \multicolumn{10}{|c|}{ Brasil Rural - Razão de concentração } \\
\hline & 1992 & 1993 & 1995 & 1996 & 1997 & 1998 & 1999 & 2001 & 2002 & 2003 \\
\hline $\begin{array}{l}\text { Trabalho } \\
\text { Principal }\end{array}$ & 0,533 & 0,575 & 0,526 & 0,548 & 0,543 & 0,540 & 0,535 & 0,529 & 0,501 & 0,532 \\
\hline $\begin{array}{l}\text { Outros } \\
\text { trabalhos }\end{array}$ & 0,607 & 0,608 & 0,608 & 0,642 & 0,591 & 0,435 & 0,543 & 0,626 & 0,519 & 0,520 \\
\hline $\begin{array}{l}\text { Aposent. e } \\
\text { pensões }\end{array}$ & 0,574 & 0,550 & 0,554 & 0,505 & 0,532 & 0,560 & 0,542 & 0,586 & 0,566 & 0,578 \\
\hline Aluguel & 0,802 & 0,879 & 0,894 & 0,865 & 0,870 & 0,877 & 0,851 & 0,904 & 0,884 & 0,890 \\
\hline Doações & 0,090 & 0,227 & 0,308 & 0,313 & 0,281 & 0,239 & 0,171 & 0,162 & 0,322 & 0,130 \\
\hline $\begin{array}{c}\text { Outros } \\
\text { rendimentos }\end{array}$ & 0,817 & 0,851 & 0,717 & 0,832 & 0,739 & 0,578 & 0,507 & 0,093 & 0,116 & 0,030 \\
\hline Gini Total & 0,547 & 0,580 & 0,540 & 0,549 & 0,547 & 0,542 & 0,538 & 0,541 & 0,510 & 0,533 \\
\hline
\end{tabular}

FONTE: Elaboração própria dos autores a partir de IBGE - dados individuais das PNADs de 1992 a 2003.

As razões de concentração para o Brasil rural apresentaram as mesmas características do Brasil, ou seja, a partir de 1998 a razão de concentração das aposentadorias e pensões é superior ao índice de Gini total, contribuindo para aumentar a desigualdade de renda.

As razões de concentração das aposentadorias e pensões para o Paraná, com exceção do ano de 2002, ficaram abaixo das razões de concentração da parcela do trabalho principal e do índice de Gini. Dessa forma, somente no ano de 2002, as aposentadorias e pensões contribuíram para aumentar a desigualdade de renda no Paraná, conforme se pode ver na tabela 9. 
SOUZA, S. C. I. DE; FERREIRA, C. R. Os rendimentos das aposentadorias...

TABELA 9. RAZÃO DE CONCENTRAÇÃO (C) NA DECOMPOSIÇÃO DO ÍNDICE DE GINI DO RENDIMENTO DOMICILIAR PER CAPITA. PARANÁ, DE 1992 A 2003.

\begin{tabular}{|c|c|c|c|c|c|c|c|c|c|c|}
\hline \multirow{2}{*}{ Parcelas } & \multicolumn{10}{|c|}{ Paraná - Razão de concentração } \\
\hline & 1992 & 1993 & 1995 & 1996 & 1997 & 1998 & 1999 & 2001 & 2002 & 2003 \\
\hline $\begin{array}{l}\text { Trabalho } \\
\text { Principal }\end{array}$ & 0,531 & 0,559 & 0,565 & 0,557 & 0,557 & 0,549 & 0,560 & 0,547 & 0,519 & 0,531 \\
\hline $\begin{array}{l}\text { Outros } \\
\text { trabalhos }\end{array}$ & 0,776 & 0,798 & 0,781 & 0,817 & 0,823 & 0,794 & 0,831 & 0,829 & 0,731 & 0,793 \\
\hline $\begin{array}{l}\text { Aposent. e } \\
\text { pensões }\end{array}$ & 0,534 & 0,517 & 0,522 & 0,541 & 0,511 & 0,542 & 0,544 & 0,546 & 0,546 & 0,510 \\
\hline Aluguel & 0,750 & 0,749 & 0,777 & 0,771 & 0,751 & 0,762 & 0,822 & 0,740 & 0,772 & 0,782 \\
\hline Doações & 0,425 & 0,390 & 0,614 & 0,545 & 0,471 & 0,527 & 0,436 & 0,408 & 0,544 & 0,512 \\
\hline $\begin{array}{c}\text { Outros } \\
\text { rendimentos }\end{array}$ & 0,728 & 0,849 & 0,803 & 0,774 & 0,742 & 0,828 & 0,691 & 0,649 & 0,506 & 0,481 \\
\hline Gini Total & 0,544 & 0,572 & 0,577 & 0,574 & 0,568 & 0,564 & 0,576 & 0,563 & 0,536 & 0,544 \\
\hline
\end{tabular}

FONTE: Elaboração própria dos autores a partir de IBGE - dados individuais das PNADs de 1992 a 2003.

No Paraná rural a razão de concentração das aposentadorias e pensões é superior ao índice de Gini nos anos de 1992, 1998 e 2002.

TABELA 10. RAZÃO DE CONCENTRAÇÃO (C) NA DECOMPOSIÇÃO DO ÍNDICE DE GINI DO RENDIMENTO DOMICILIAR PER CAPITA. PARANÁ RURAL, DE 1992 A 2003.

\begin{tabular}{|c|c|c|c|c|c|c|c|c|c|c|}
\hline \multirow{2}{*}{ Parcelas } & \multicolumn{10}{|c|}{ Paraná Rural - Razão de concentração } \\
\hline & 1992 & 1993 & 1995 & 1996 & 1997 & 1998 & 1999 & 2001 & 2002 & 2003 \\
\hline $\begin{array}{l}\text { Trabalho } \\
\text { Principal }\end{array}$ & 0,455 & 0,527 & 0,486 & 0,499 & 0,505 & 0,466 & 0,496 & 0,564 & 0,504 & 0,543 \\
\hline $\begin{array}{l}\text { Outros } \\
\text { trabalhos }\end{array}$ & 0,647 & 0,732 & 0,670 & 0,660 & 0,750 & 0,668 & 0,720 & 0,750 & 0,551 & 0,581 \\
\hline $\begin{array}{l}\text { Aposent. e } \\
\text { pensões }\end{array}$ & 0,605 & 0,513 & 0,488 & 0,452 & 0,437 & 0,540 & 0,440 & 0,522 & 0,551 & 0,557 \\
\hline Aluguel & 0,739 & 0,769 & 0,706 & 0,561 & 0,724 & 0,622 & 0,738 & 0,790 & 0,539 & 0,880 \\
\hline Doações & 0,323 & 0,167 & 0,234 & 0,302 & 0,074 & 0,353 & 0,179 & 0,633 & 0,556 & $-0,371$ \\
\hline $\begin{array}{c}\text { Outros } \\
\text { rendimentos }\end{array}$ & 0,806 & 0,688 & 0,757 & 0,490 & 0,723 & 0,923 & 0,505 & 0,614 & 0,438 & 0,339 \\
\hline Gini Total & 0,496 & 0,538 & 0,496 & 0,500 & 0,511 & 0,505 & 0,501 & 0,569 & 0,513 & 0,557 \\
\hline
\end{tabular}

FONTE: Elaboração própria dos autores a partir de IBGE - dados individuais das PNADs de 1992 a 2003.

A figura 1 mostra a participação, em termos percentuais, dos componentes: trabalho principal, aposentadorias e pensões e demais parcelas para a formação do índice de Gini total, no Brasil, entre 1992 e 2003. 
FIGURA 1. PERCENTAGENS DE CONTRIBUIÇÃO DAS PARCELAS TRABALHO PRINCIPAL, APOSENTADORIAS E PENSÕES E DEMAIS PARCELAS NA FORMAÇÃO DO ÍNDICE DE GINI TOTAL. BRASIL, 1992 A 2003.

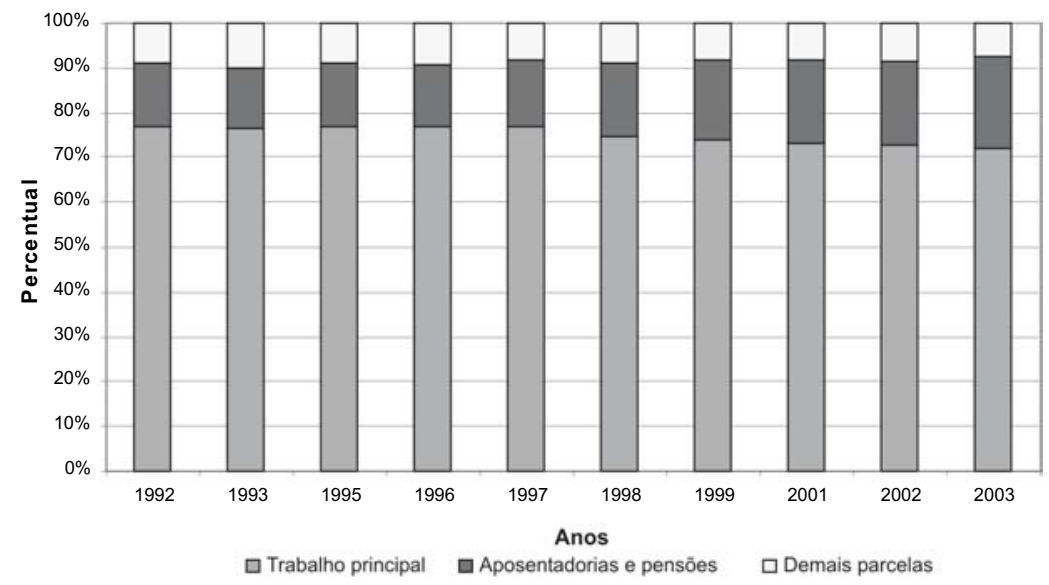

O rendimento do trabalho principal é, em todo o período, o componente com a maior participação na formação do índice de Gini do rendimento domiciliar per capita, seguido pelo rendimento de aposentadorias e pensões.

Ao longo do período analisado verifica-se que os rendimentos do trabalho principal, em média, representam $76,7 \%$ do rendimento total e originam a maior parcela do índice de Gini, participando com $75 \%$.

Entre os demais componentes do rendimento, as aposentadorias e pensões vêm a seguir, representando, em média, $16,4 \%$ do rendimento total, originando a segunda maior parcela do índice de Gini, com 16,3\%. Em 1992, a contribuição dessa parcela para o índice de Gini foi de $14 \%$, e acentuou o seu crescimento na segunda metade dos anos 90, principalmente nos anos de 1998 e 1999. No início do novo século observa-se que esse componente continua com tendência de crescimento, chegando em 2003 com uma participação no índice de Gini total de 20,2\%, sendo esse o maior percentual de todo o período analisado.

Entre 1992 e 2003, a parcela do índice de Gini do rendimento domiciliar per capita para o Brasil, referente ao rendimento do trabalho principal, diminuiu $4,7 \%$, ao mesmo tempo em que a parcela referente ao rendimento de aposentadorias e pensões aumenta $6,2 \%$.

Na figura 2, verifica-se a participação percentual do índice de Gini na formação do índice de Gini global dos componentes do rendimento domiciliar per capita para o Brasil rural, de 1992 a 2003. 
SOUZA, S. C. I. DE; FERREIRA, C. R. Os rendimentos das aposentadorias...

A maior participação no índice de Gini total é a do trabalho principal, com um percentual semelhante ao do Brasil. Verifica-se que no período também houve um decrescimento de 6,7\% em sua participação.

Com relação à participação das aposentadorias e pensões, observa-se que em sete dos dez anos analisados, a parcela aposentadorias e pensões rurais foram superiores à do Brasil, com destaque para os anos de 2001, 2002 e 2003.

FIGURA 2. PERCENTAGENS DE CONTRIBUIÇÃO DAS PARCELAS TRABALHO PRINCIPAL, APOSENTADORIAS E PENSÕES E DEMAIS PARCELAS NA FORMAÇÃO DO ÍNDICE DE GINI TOTAL. BRASIL RURAL, 1992 A 2003

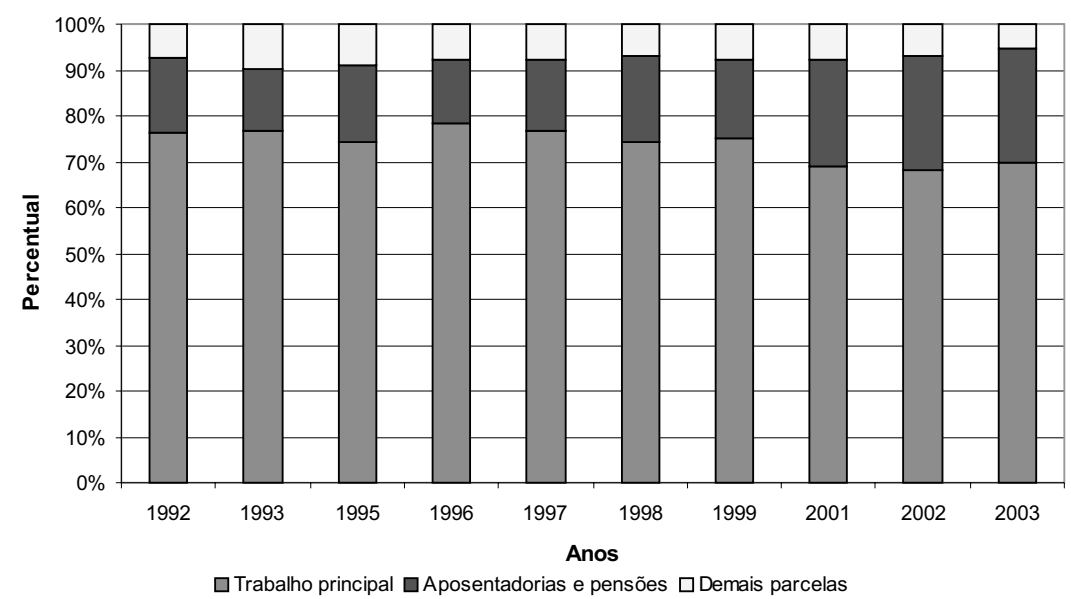

A participação percentual das parcelas do índice de Gini para o trabalho principal e aposentadorias e pensões para o estado do Paraná pode ser vista na figura 3. O rendimento do trabalho principal é, em todo o período, o componente com a maior participação na formação do índice de Gini do rendimento domiciliar per capita, acompanhado pelo rendimento de aposentadorias e pensões. 
FIGURA 3. PERCENTAGENS DE CONTRIBUIÇÃO DAS PARCELAS TRABALHO PRINCIPAL, APOSENTADORIAS E PENSÕES E DEMAIS PARCELAS NA FORMAÇÃO DO ÍNDICE DE GINI TOTAL. PARANÁ, 1992 A 2003

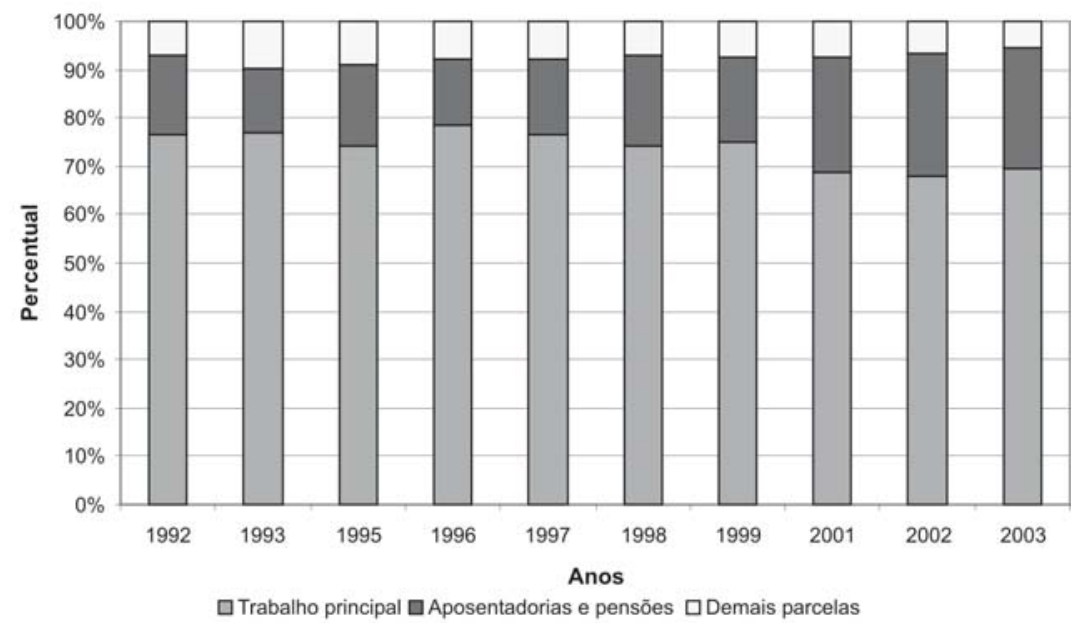

Ao longo do período observado, o rendimento do trabalho principal representou, em média, $79,3 \%$ do rendimento total e $77,3 \%$ da parcela do índice de Gini. As aposentadorias e pensões representaram, em média, $12,9 \%$ da renda total e originaram $12,3 \%$ da parcela do índice de Gini, embora no período 2001 a 2003 sua participação tenha ficado na casa dos $15 \%$.

A parcela do índice de Gini do rendimento domiciliar per capita para o Paraná, referente ao rendimento do trabalho principal, diminuiu 6,4\%, ao mesmo tempo que a parcela referente ao rendimento de aposentadorias e pensões aumentou $4 \%$.

No Paraná rural, a contribuição de cada parcela de rendimento na formação do índice de Gini, entre 1992 e 2003, pode ser verificada na figura 4. Observa-se que a parcela do trabalho principal, participou com o maior percentual em todo o período, pois seu rendimento cresceu $0,9 \%$ entre os anos extremos do período analisado.

A participação da parcela "aposentadorias e pensões" foi declinante entre 1993 e 1997, voltando a crescer a partir de 1998 e acentuando esse crescimento entre 2001 e 2003. No período 1992 a 2003, o rendimento dessa parcela também cresceu $0,9 \%$. 
SOUZA, S. C. I. DE; FERREIRA, C. R. Os rendimentos das aposentadorias...
FIGURA 4. PERCENTAGENS DE CONTRIBUIÇÃO DAS PARCELAS TRABALHO PRINCIPAL, APOSENTADORIAS E PENSÕES E DEMAIS PARCELAS NA FORMAÇÃO DO ÍNDICE DE GINI TOTAL. PARANÁ RURAL, 1992 A 2003

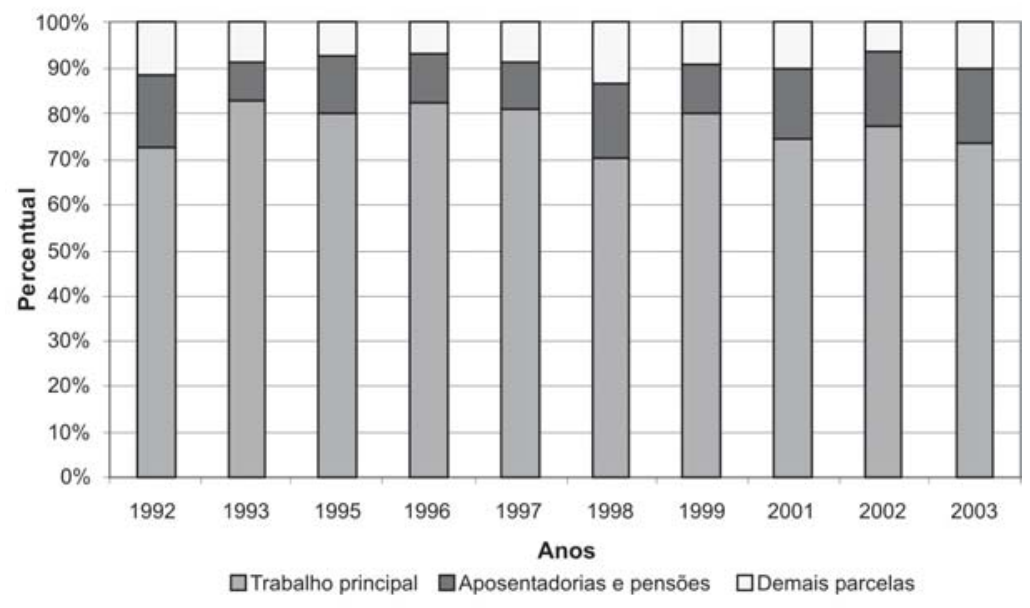

\section{Considerações finais}

Os resultados da medida dos componentes do rendimento domiciliar per capita para o Brasil, Brasil rural, Paraná e Paraná rural apontaram uma maior participação da parcela do rendimento do trabalho principal, seguida pela parcela de aposentadorias e pensões, em todo o período observado, destacando o aumento significativo dessa última.

A participação percentual dos rendimentos da parcela aposentadorias e pensões do Brasil rural no rendimento total é superior à do Brasil em sete dos dez anos analisados. Destaca-se que entre 2001 e 2003 essa participação ficou bem acima do percentual médio verificado entre 1992 e 1999. No Paraná rural, a participação da renda das aposentadorias é maior que a do Paraná em sete dos dez anos analisados, evidenciando a importância desse rendimento para o setor rural paranaense.

O estudo da concentração de renda, respaldado pela análise do comportamento da razão de concentração de cada parcela de rendimento domiciliar per capita em relação ao índice de Gini total, indica que, no período analisado, o Brasil apresentou cinco anos em que a razão de concentração foi maior que o índice de Gini total. No Brasil rural aconteceu em sete anos, no Paraná em um ano e no Paraná rural em três anos. Isso significa que, a despeito de identificar, em cinco anos, a concentração de renda provocada pelas aposentadorias no Brasil, o trabalho evidencia um comportamento diferente no Estado do Paraná como um todo, com exceção de 2002. No espaço rural paranaense, a contri- 
buição das aposentadorias para a concentração de rendimentos se dá nos anos de 1992, 1998 e 2002.

Ademais, há contribuição significativa das aposentadorias e pensões na formação do índice de Gini em todo o período analisado, com clara tendência de crescimento no final da década de 90 e início do século XXI. Esse comportamento foi verificado na decomposição do índice de Gini para o Brasil, Brasil rural, Paraná e Paraná rural.

O rendimento do trabalho principal teve um comportamento inverso para o Brasil, Brasil rural e Paraná. Todavia, no Paraná rural, pode-se observar que a sua participação no índice de Gini total não sofreu queda, com exceção do ano de 1998, indicando a necessidade de estudos mais profundos.

Para o Brasil, Brasil rural e Paraná, essa diferença de comportamento das duas distribuições, ou seja, a queda de participação do trabalho principal e crescimento de aposentadorias e pensões na formação do índice de Gini, pode ser explicada através da participação decrescente dos rendimentos do trabalho principal e da participação crescente dos rendimentos das aposentadorias e pensões no rendimento domiciliar per capita. Cabe esclarecer que, embora o rendimento das aposentadorias e pensões tenha obtido ganho real no Brasil e no Paraná no pós1995, essa trajetória de avanço perde fôlego a partir de 2002, particularmente no Paraná.

O comportamento da renda das aposentadorias e pensões está associado ao envelhecimento da população e essa tendência é de crescimento, porque a população brasileira e paranaense tem apresentado baixas taxas de fecundidade, aumento de longevidade e urbanização acelerada, levando a um maior crescimento da população idosa em relação aos demais grupos etários.

Há que salientar também o movimento de reestruturação da política social brasileira, particularmente a da previdência social, com a Constituição de 1988, e o aumento do volume de contribuintes estimulado na década de 70, que resultou no aumento de beneficiários na década de 90, ao mesmo tempo em que se operavam transformações no mercado de trabalho que levaram à redução da capacidade contributiva dos cidadãos brasileiros para a previdência social.

Assim, a combinação de mudanças na composição do mercado de trabalho, crescente informalização, flexibilização das relações trabalhistas e crescimento da população idosa, somada aos problemas existentes nos critérios e requisitos do sistema previdenciário, tornam frágil o sistema vigente, denotando uma conjunção de crescimento do déficit previdenciário e concentração de renda resultante das aposentadorias. 
SOUZA, S. C. I. DE; FERREIRA, C. R. Os rendimentos das aposentadorias...

Os dados comprovam, no entanto, que esse último aspecto não é sentido pela população paranaense.

\section{Referências}

AZEREDO, B. (1998). Políticas públicas de emprego: a experiência brasileira. São Paulo: ABET.

BARROS, R. P. \& CARVALHO, M. \& PESSOA, S. \& MENDONÇA, R. (2006). Conseqüências e causas imediatas da queda recente da desigualdade de renda brasileira. Rio de Janeiro: IPEA. URL: www.ipea.gov.br. Acesso em: o9 de agosto de 2006.

BRASIL. Ministério da Fazenda. Secretaria de Política Econômica. (2005). Orçamento social do governo federal: 2001-2004. Brasília.

CONJUNTURA ECONÔMICA. (2004). Rio de Janeiro: FGV, 58(5). . (2006). Rio de Janeiro: FGV, 6o(2).

DAIN, S. \& SOARES, L. T. (1998). "Reforma do Estado e políticas públicas: relações intergovernamentais e descentralização desde 1988." In OLIVEIRA, M. A. (org.). Reforma do Estado e políticas de emprego no Brasil. Campinas: Unicamp.

DRAIBE, S. M. (1993). Qualidade de vida e reformas de programas sociais: o Brasil no cenário latino-americano. Lua Nova 31.

DUPAS, Gilberto (1999). Economia global e exclusão social. São Paulo: Paz e Terra.

ERCELAWN, A. (1984). "Income inequality in rural Pakistan: a study of sample villages." Pakistan Journal of Applied Economics 3:1-28.

ESPING-ANDERSEN, Gosta. (1991). "As três economias do welfare state." Lua Nova 24.

FAGNANI, E. (1999). "Ajuste econômico e financiamento da política social brasileira: notas sobre o período 1993/98." Campinas. Economia e Sociedade 13: 155-178.

(1997). "Política social e pactos conservadores no Brasil: 1964/92." Campinas. Economia e Sociedade 8: 183-238.

FEI, J. C. \& RANIS, G. \& KUO, S. W. Y. (1978). "Growth and the family distribution of income by factor components." The Quarterly Journal of Economics 92: 17-53.

FERREIRA, C. R. (2003). Participação das aposentadorias e pensões na desigualdade da distribuição da renda no Brasil no período de 1981 a 2001. Piracicaba. Tese (Doutorado) - Escola Superior de Agricultura "Luiz de Queiroz”, Universidade de São Paulo. 136p.

FERREIRA, C. R. \& SOUZA, S. C. I. (2004a). "Previdência social e desigualdade." In XXXII ENCONTRO NACIONAL DE ECONOMIA, 2004, João Pessoa. Anais... João Pessoa: ANPEC. 
FERREIRA, C. R. \& SOUZA, S. C. I. (2004b). "A contribuição das parcelas do rendimento domiciliar per capita para a desigualdade no Brasil, Região Sul e Estado do Paraná.” Revista Paranaense de Desenvolvimento 106: 2948.

GIAMBIAGI, F. et al. (2004). Diagnóstico da previdência social no Brasil: o que foi feito e o que falta reformar? Rio de Janeiro: IPEA. 44 p. (Texto para Discussão, 1050).

GIOVANNI, G. (1998). "Sistemas de proteção social: uma introdução conceitual.” In OLIVEIRA, M. A. (org.). Reforma do Estado e políticas de emprego no Brasil. Campinas: Unicamp.

HOFFMANN, R. (1988). “A subdeclaração dos rendimentos.” SEADE. São Paulo em Perspectiva 2(1): 50-54.

HOFFMANN, R. (2002a). Desigualdade no Brasil: a contribuição das aposentadorias. URL: www.eco.unicamp.br/projetos/rurbano.html. Acesso em: 17 de outubro de 2002.

HOFFMANN, R. (2002b). "Posse da terra, renda e condições de vida na agricultura brasileira” (compact disc). In CONGRESSO BRASILEIRO DE ECONOMIA E SOCIOLOGIA RURAL, 40., Passo Fundo, 2002. Anais... Brasília: SOBER.

IBGE - INSTITUTO BRASILEIRO DE GEOGRAFIA E ESTATÍSTICA. (1992-93, 1995-99, 2001, 2002 e 2003). Pesquisa Nacional por Amostra de Domicílios (compact disc). Rio de Janeiro.

. (2006). Síntese dos indicadores sociais 2003. URL: www.ibge.gov.br. Acesso em: 20 de julho de 2006.

MEDEIROS, Marcelo. (2006). Uma introdução às representações gráficas da desigualdade de renda. Rio de Janeiro: IPEA. URL: www.ipea.gov.br. Acesso em: 09 de agosto de 2006.

MARIANO, J. L. \& LIMA, R. C. (1998). “A desigualdade da renda rural no Nordeste: análise da desagregação do coeficiente de Gini e da sensibilidade do índice de bem-estar de Sen.” Análise Econômica 16(29): 103-118.

MARQUES, R. M. (1997). A proteção social e o mundo do trabalho. São Paulo: Bienal.

NEDER, H. D. (2001). "Os efeitos das atividades não-agrícolas na distribuição de renda no meio rural" (compact disc). In CONGRESSO BRASILEIRO DE ECONOMIA E SOCIOLOGIA RURAL, 39., Recife, 2001. Anais... Brasília: SOBER.

OLIVEIRA, F. (1998). Os direitos do anti-valor: a economia política da hegemonia imperfeita. Rio de Janeiro: Vozes.

PYATT, G. \& CHEN, C. \& FEI, J. (1980). "The distribution of income by factor components." The Quarterly Journal of Economics 95(3): 451-473.

RAMOS, L \& BRITTO, M. (2004). O funcionamento do mercado de trabalho metropolitano brasileiro no período 1991-2002: tendências, fatos estilizados e mudanças estruturais. Rio de Janeiro: IPEA.

RAMOS, L \& REIS, J. G. A. (1997). Emprego no Brasil nos anos 9o. Rio de 
SOUZA, S. C. I. DE; FERREIRA, C. R. Os rendimentos das aposentadorias...

Janeiro: IPEA.

SINGER, P. (1999). Globalização e desemprego: diagnóstico e alternativas. São Paulo: Contexto.

SOUZA, S. C. I. (2002). A qualificação do trabalhador e a política pública de emprego e trabalho. Tese (Doutorado) - Pontifícia Universidade Católica de São Paulo.

VALLE, B. (1998). "Políticas de mercado de trabalho no Brasil: a experiência do Proger." In OLIVEIRA, M. A. (org.). Reforma do Estado e políticas de emprego no Brasil. Campinas: Unicamp.

Recebido em: 24 abr. 2006 Aceite em: 7 ago. 2006 